\title{
Study of Relations between Computer Experience and Readiness to Access Internet Resources
}

\author{
Andrzej Malachowski \\ University of Economics, Wroclaw, Poland \\ andrzej.malachowski@ae.wroc.pl
}

\begin{abstract}
The paper presents results of studies among computer users, demonstrating a remarkable relation between history of computer use (computer experience) and readiness to access Internet resources (Internet access). The observed relation, referred to as 'Internet entry delay syndrome', may be described as follows: the greater the user's computer experience, the longer it takes him/her to decide on accessing Internet and using it on a regular basis. The delay is markedly shorter for inexperienced computer users. The results of the study can be invaluable for Internet Service Providers (ISPs), allowing for more precise design of network infrastructure, as well as for local administration authorities striving to implement the policy of information society through development of information structures and services and improving Internet access on local and regional scale.
\end{abstract}

Keywords: computer users, Internet users, Internet (users) entry delay syndrome.

\section{Introduction}

Results of studies of Polish Internet users, published in February 2006 (Malachowski, 2006), displayed a number of astonishing relations that required further analyses and examinations. This paper presents a step-by-step account and analysis of chosen results of the aforementioned study, followed by broader theoretical reinterpretation and final conclusions. Some of the conclusions are of methodological nature and may serve to improve Internet research techniques. The issues discussed herein are general and may be applied in studies on populations of Internet users in any European country.

\section{Basic Study Results}

The fundamental purpose of the aforementioned study was to obtain an in-depth description of a virtual customer and his/her most typical actions in the virtual environment, i.e. the most frequent behavioral aspects of operational Internet activities. The study was conducted on the basis of an Internet survey, published on a dedicated web page. The survey questions (47) were arranged in

Material published as part of this publication, either on-line or in print, is copyrighted by the Informing Science Institute. Permission to make digital or paper copy of part or all of these works for personal or classroom use is granted without fee provided that the copies are not made or distributed for profit or commercial advantage AND that copies 1) bear this notice in full and 2) give the full citation on the first page. It is permissible to abstract these works so long as credit is given. To copy in all other cases or to republish or to post on a server or to redistribute to lists requires specific permission and payment of a fee. Contact Publisher@InformingScience.org to request redistribution permission. six main thematic groups (Malachowski, 2006):

- basic Internet user details,

- details on computer experience and Internet access,

- behavioral data (ways of using the Internet), 
- perspectives for development of Internet activities,

- determining the most appreciated features of the Internet,

- determining the most notable faults of the Internet.

The respondent answers were stored in a separate file on the server. To direct respondents to the web page address hosting the survey, principles of the so-called viral marketing were used: first ten randomly chosen Internet users were sent an e-mail with details of the planned study and the address of the survey hosting page. Further spread of the message was spontaneous and uncontrolled. Consequently, within a short time frame, 420 respondents visited the web page and completed the survey. Several subsequent tests were conducted to confirm the representative character of the respondent population in regard to the Polish Internet user base, accounting for such features as age group, level of education, place of residence, place of Internet access, etc.

Due to constrained framework of this discussion, the paper addresses only the subject issue of relation between the level of computer experience and the history (time span) of Internet use in the studied (representative) population of Polish Internet users. Results of computer experience expressed in years of computer use, total and by gender, are shown in Table 1.

Table 1: Computer experience (in years) by gender

\begin{tabular}{|c|c|c|c|c|c|c|c|}
\hline \multirow[t]{3}{*}{ No. } & \multirow[t]{2}{*}{ Experience } & \multicolumn{2}{|c|}{ Total } & \multicolumn{2}{|c|}{ Women } & \multicolumn{2}{|c|}{ Men } \\
\hline & & $\mathbf{n}_{\mathbf{i}}$ & $\%$ & $\mathrm{n}_{\mathrm{k}}$ & $\%$ & $\mathrm{n}_{\mathrm{m}}$ & $\%$ \\
\hline & 1 & 2 & 3 & 4 & 5 & 6 & 7 \\
\hline 1 & up to 1 year & 5 & $1.2 \%$ & 3 & $3.4 \%$ & 2 & $0.6 \%$ \\
\hline 2 & 2-3 years & 23 & $5.6 \%$ & 4 & $4.5 \%$ & 19 & $5.9 \%$ \\
\hline 3 & 4-6 years & 95 & $23.0 \%$ & 25 & $28.4 \%$ & 70 & $21.6 \%$ \\
\hline 4 & $\begin{array}{l}\text { more than } 6 \\
\text { years }\end{array}$ & 289 & $70.2 \%$ & 56 & $63.7 \%$ & 233 & $71.9 \%$ \\
\hline & Total & 412 & $100.0 \%$ & 88 & $100.0 \%$ & 324 & $100.0 \%$ \\
\hline
\end{tabular}

Source: (Malachowski, 2006)

It must be noted that in the studied population, users show relatively good computer experience. More than $93 \%$ of them have used computers for not less than 4 years, while the average time span (experience) of using computers amounts to 6.2 years.

At the same time, more than $\mathbf{7 0 \%}$ of the respondents report having used the computer for over $\mathbf{6}$ years. Such strong asymmetry in computer experience spread signals the need to supplement the research horizon scheme with new time spans. This issue will be addressed later on.

Study of Internet usage span is shown in synthetic form in Table 2. 
Table 2: Internet use (in years) by gender

\begin{tabular}{|c|c|c|c|c|c|c|c|}
\hline \multirow[t]{3}{*}{ No. } & \multirow[t]{2}{*}{ Internet use } & \multicolumn{2}{|c|}{ Total } & \multicolumn{2}{|c|}{ Women } & \multicolumn{2}{|c|}{ Men } \\
\hline & & $\mathbf{n}_{\mathbf{i}}$ & $\%$ & $\mathrm{n}_{\mathrm{k}}$ & $\%$ & $\mathrm{n}_{\mathrm{m}}$ & $\%$ \\
\hline & 1 & 2 & 3 & 4 & 5 & 6 & 7 \\
\hline 1 & up to 1 year & 23 & $5.6 \%$ & 8 & $9.2 \%$ & 15 & $4.6 \%$ \\
\hline 2 & 2-3 years & 160 & $38.9 \%$ & 30 & $34.5 \%$ & 130 & $40.1 \%$ \\
\hline 3 & 4-6 years & 170 & $41.4 \%$ & 36 & $41.4 \%$ & 134 & $41.4 \%$ \\
\hline 4 & $\begin{array}{l}\text { more than } 6 \\
\text { years }\end{array}$ & 58 & $14.1 \%$ & 13 & $15.0 \%$ & 45 & $13.9 \%$ \\
\hline & Total & 411 & $100.0 \%$ & 87 & $100.0 \%$ & 324 & $100.0 \%$ \\
\hline
\end{tabular}

Source: (Malachowski, 2006)

The majority of respondents (nearly $\mathbf{9 5 \%}$ ) report having used the Internet for more than 1 year. This group is categorized as heavy users. The average span of using Internet in the group under study amounted to 4.1 years.

Contrasting the data presented in the above tables brings forth some interesting relations.

Let us first consider differences in quantity distribution between the two time spans in the last range (more than 6 years). Comparing the tables 1 and 2, it is evident that the majority, i.e. 80\% [100\% - (58:289) x 100\%] of Internet users (Table 2) reporting less than 6 years (shorter time span) of Internet activity has used the computer for more than 6 years (Table 1). Hence, the substantial majority $(80 \%)$ of Internet users reporting less than 6 years of using this medium simultaneously reports considerably longer time span of computer use (more than 6 years). In other words, respondents using Internet for more than 6 years (58- see Table 2) represent only $\mathbf{2 0 \%}$ of respondents using computers for the similar time span of more than 6 years (289- see Table 1). It is evident (Table 2 vs. Table1), that distribution of both time spans in the range of up to 6 years are (and have to be) considerably divergent.

The correlation coefficient between the length of computer use and that of Internet use for the collected sample is (-0.19). Hence, the relation is of weak negative character, i.e. the longer the time span of using computers, the relatively shorter is the reported time span of using Internet. This relation constitutes the so-called (Internet) entry delay syndrome, an issue that will be discussed further on.

\section{Extended Study Results}

To better illustrate the observed relation and describe the nature of 'entry delay syndrome', the results reported in the study (Malachowski, 2006) have been extended. In the first stage, relations between computer use and Internet use (in years) are shown in the form of histogram charts. As already mentioned, the averages for both values under study in the respondent population are: 6.2 years for computer use time span and 4.1 years for Internet use time span. Consequently, the respondents after an average of $\mathbf{2 . 1}$ year of using the computer decide to use the Internet. Such is the average 'delay' value of Internet entry in accordance with the studies (Malachowski, 2006). It 
may be foreseen that the delay value will be systematically lowered with further popularization of the Internet medium - a trait confirmed also in the aforementioned study.

In order to compare the distribution of both time spans (computer use and Internet use), data from Tables. 1 and 2 were collated in the histogram chart form shown in Figure 1.

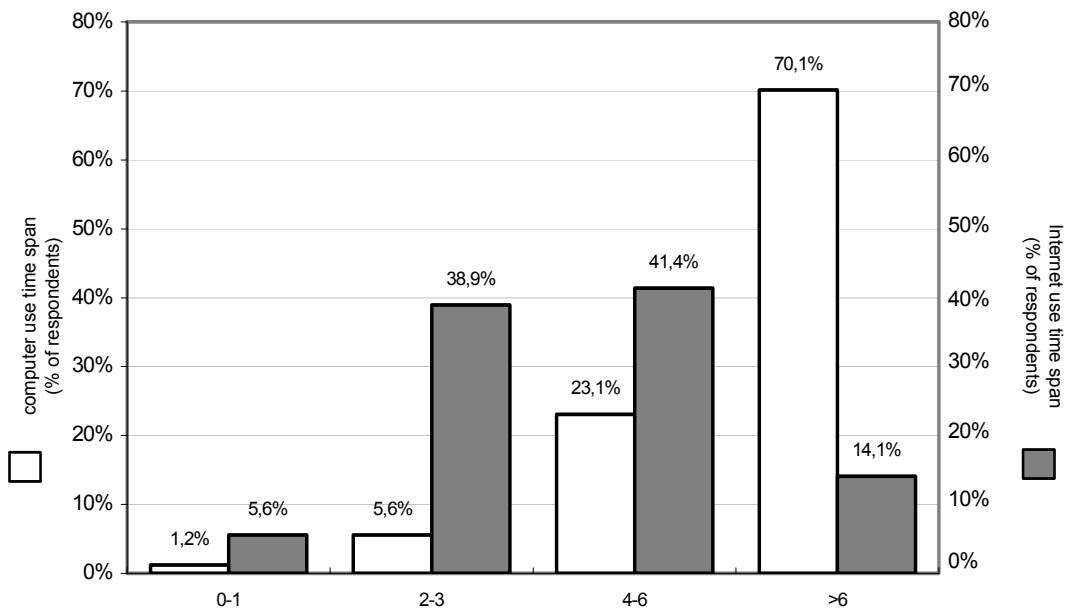

Figure 1: Histograms of distribution: computer use and Internet use

It is evident that the distribution of computer use time spans shows considerable asymmetry (right offset), while distribution of Internet use time spans is moderately symmetrical (with slight left offset). This is confirmed by the respective skewness coefficient: $\mathrm{SC}$ (comp.) $=1.51$ and $\mathrm{SC}($ Inter. $)=-0.18$.

The asymmetry of computer use distribution brings forth an important issue to be regarded in future studies on the subject: the time ranges for computer use studies should be extended to cover the margin of $8-10,10-15,15-20$ and even more than 20 years! The substantiation is twofold: age distribution, with share of users aged 30 and older is considerable (own research and the study reported in (MEGAPANEL, 2004); and history of PC evolution reaching back to the early 1990ies.

On the other hand, based on the distribution of Internet use time span (moderately symmetrical), it may be reasonable to postulate extending the time ranges (beyond the 6-8 years range) with an additional range of more than 8 years. The Polish dominant telecom TP S.A. opened public Internet dial-up access as late as 1996, with resulting rapid increase of Internet users; by the second half of 1998 the number of Internet-enabled computers (IP addresses) exceeded the 100 thousand mark. This is considered as a relative borderline for Polish Internet popularization (Czajkowski, 2002). Hence, the Internet use time span in Poland is within the top range of 8-10 years.

To explain the issue of 'delay' in Internet entry and the observed relations between computer use time span and that of the Internet use, an 'inverted' cumulated series of distributions of both time spans is used (Figure 2.). 


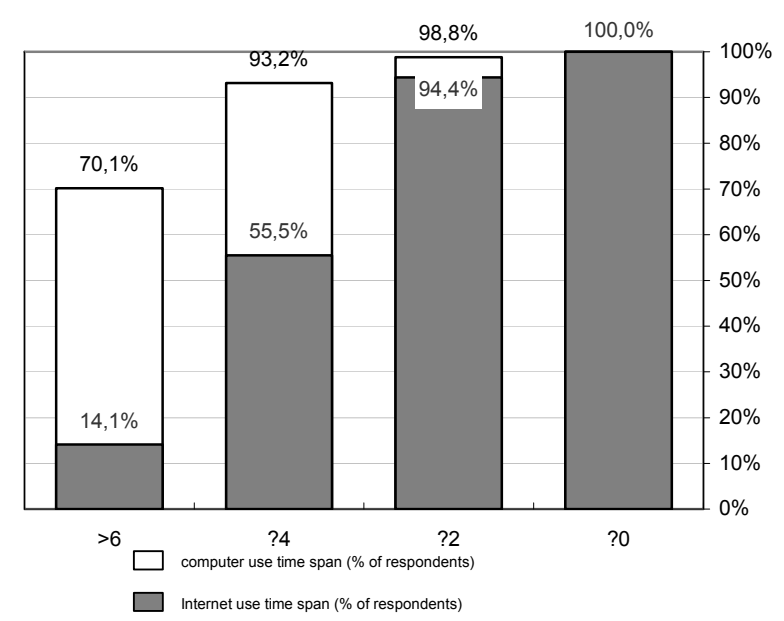
Figure 2: Comparison of cumulated time spans: computer use
and Internet use in the studied user population

From the analysis of both cumulated series, several important conclusions can be made:

a. only ca. $20 \%$ of computer users $\{(14.1: 70.2) \times 100 \%\}$ in the time span range of $\geq 6$ years reports similar time span of Internet use, the remaining users (ca. 80\%) report shorter time span of Internet use, which shows that a considerable number of computer users decide to access the Internet after a marked delay,

b. in the cumulated group of respondents using computers for a time span of $\geq 4$ years, nearly $60 \%\{(55.5: 93.2) \times 100 \%\}$ report similar time span of Internet use, $40 \%$ of those report shorter time span of Internet use, which also shows a considerable delay in accessing the Internet,

c. in the cumulated group of respondents using computers for a time span of $\geq 2$ years, over $95 \%$ of the users $\{(94.4: 98.8) \times 100 \%\}$ report similar time span of Internet use, while 5\% still report shorter time span of Internet use; hence also in regard to this population group, a certain delay in accessing the Internet was found.

The above analysis substantiates another assumption: the delay in accessing the Internet decreases with shorter computer use; in other words, the shorter the time span of computer use, the closer it is to the time span of Internet use (while remaining markedly longer).

Accounting for the postulated extension of the studied time span horizons: computer use to the limit of $>20$ years and Internet use to 10 years, an attempt at estimation of the data from Tables 1 and 2 was made for these distributions. In the study by Kozyra (Kozyra, 2006), beta-distribution was used to estimate numerical strength of both new ranges (using StatCalc software). Presentation of detailed analysis of methods chosen and calculations made is beyond the scope of this paper, let us come to the actual presentation of verified results. Du to scope restraints, only the estimations of new time span distributions are presented: i.e. computer use and Internet use for the whole studied sample, excluding the four subsequent distributions in regard to women and men. For the detailed account of calculations made and results obtained for these estimations, see: (Kozyra, 2006).

The resultant data corresponding to the estimation of time span distribution in computer use are shown in Table 3 (Kozyra, 2006). 
Table 3: Estimation of distribution: time span of computer use

\begin{tabular}{|r|r|r|}
\hline Ranges & Unitarization & \multicolumn{1}{l|}{ Total ni } \\
\hline 0 & 0 & 0 \\
\hline 1 & 0.05 & 2.1 \\
\hline 3 & 0.15 & 26.3 \\
\hline 6 & 0.3 & 92.5 \\
\hline 10 & 0.5 & 155.1 \\
\hline 14 & 0.7 & 104.8 \\
\hline 17 & 0.85 & 27.9 \\
\hline 19 & 0.95 & 3.2 \\
\hline 20 & 1 & 0.1 \\
\hline & Sum & 412 \\
\hline parameters & Alpha & 2.551362 \\
\hline & Beta & 3.563831 \\
\hline & chi-square & 2.240238 \\
\hline & p-value & 0.13446 \\
\hline & aver. val. & 0.417217 \\
\hline & source: (Kozyra, 2006) \\
\hline & standard deviation & 0.184859 \\
\hline & kewness & 0.220731 \\
\hline & & 2.40682 \\
\hline & &
\end{tabular}

As seen in Table 3, adjustment of beta-distribution with data on computer use is good. The resulting average time span of computer use is $20 * 0.414777=\mathbf{8 . 3}$ years (with the original calculation of 6.2 years). A density chart of the resulting beta-distribution is presented in Figure 3. 


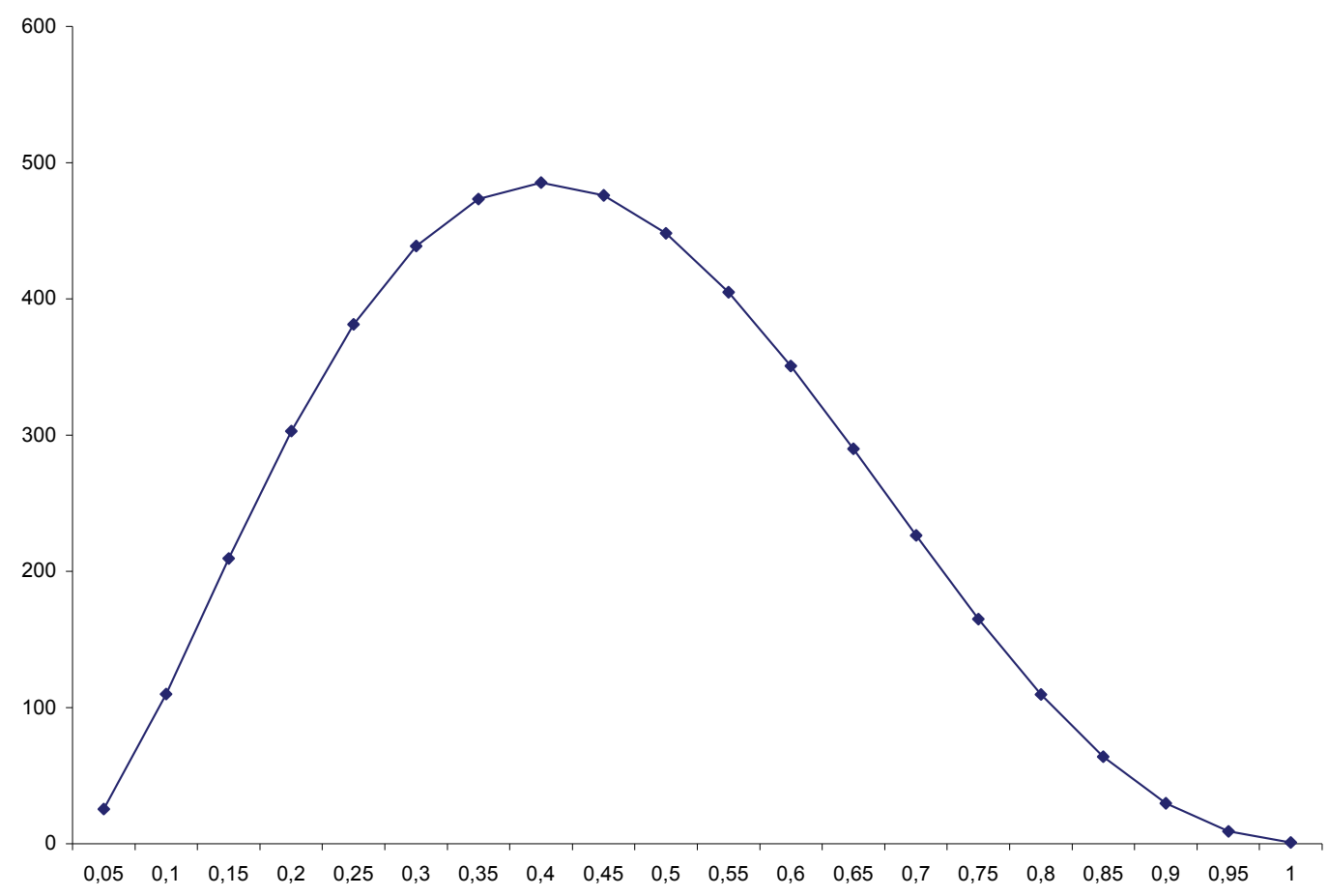

Figure 3: Beta distribution for total computer use time span Source: (Kozyra,2006)

Analogical calculations were made for estimation of Internet use time span distribution. Results are presented in Table 4.

Table 4: Estimation of distribution: time span of Internet use

\begin{tabular}{|r|r|r|}
\hline \multirow{2}{*}{ Ranges } & Unitarization & \multicolumn{2}{|c|}{ Total ni } \\
\hline 0 & 0 & 0 \\
\hline 1 & 0.1 & 28.1 \\
\hline 3 & 0.3 & 141.2 \\
\hline 6 & 0.6 & 188.7 \\
\hline 8 & 0.8 & 47.0 \\
\hline 9 & 0.9 & 5.4 \\
\hline 10 & 1 & 0.6 \\
\hline & Sum & 411 \\
\hline parameters & Alpha & 1.957023 \\
\hline & Beta & 3.411066 \\
\hline & & 5.856029 \\
& chi-square & 1 \\
\hline & p-value & 0.015523 \\
& aver. Val. & 0.364566 \\
\hline & Skewness & 0.385491 \\
\hline & Kurtosis & 2.47926 \\
\hline
\end{tabular}

Source: (Kozyra, 2006) 
The estimated average of Internet use time span in this case is 3.6 years and is lower than the original calculation (4.1 years). Density chart of the resulting beta-distribution of Internet use total time span is presented on Figure 4.

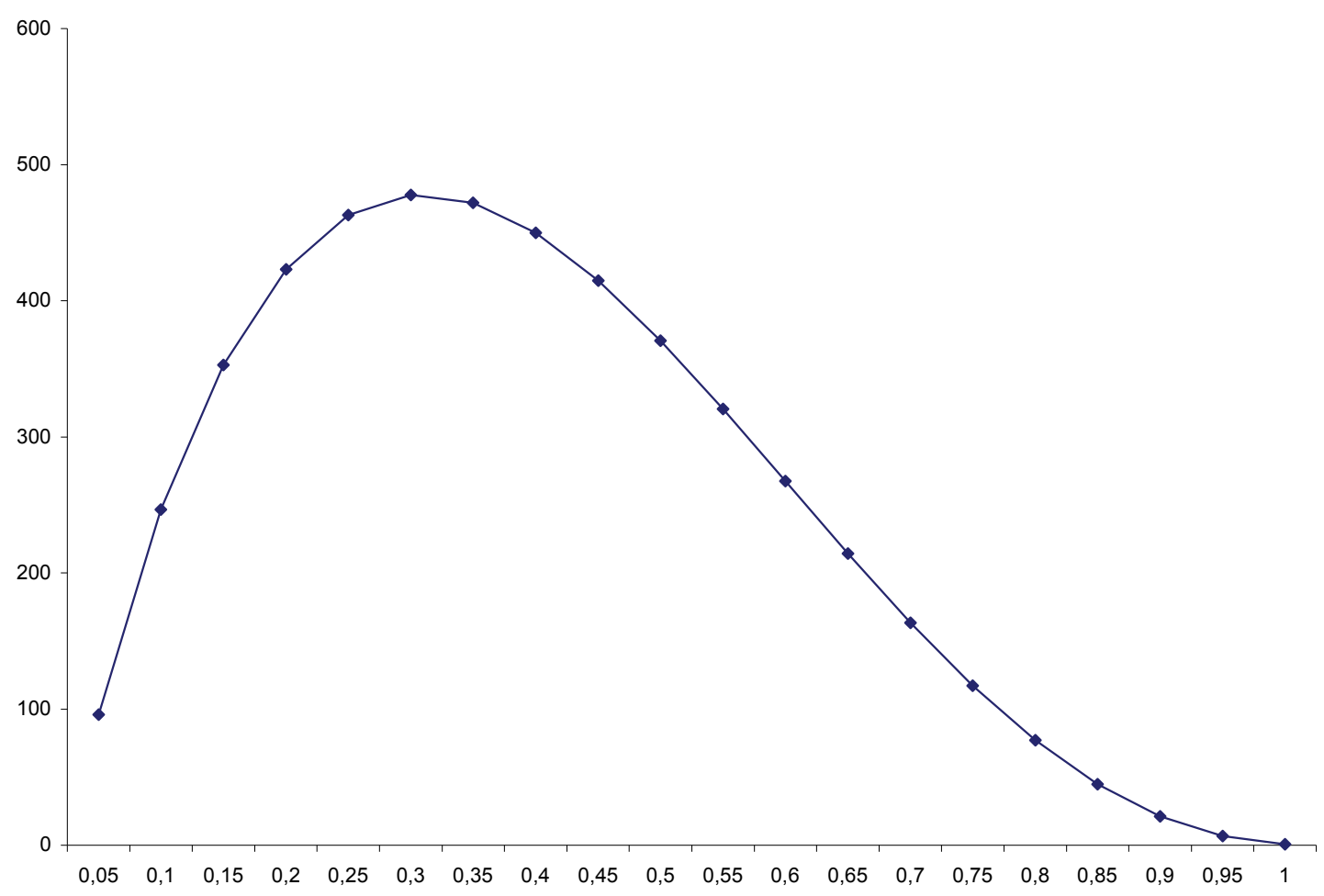

Figure 4: Beta distribution for total Internet use time span

Source: (Kozyra, 2006)

The chart shows strong leftward asymmetry (more pronounced than that of the original study). To sum up, the obtained beta distribution is consistent with the data.

\section{Conclusions}

The conducted research (original and supplementary) brings forth several important conclusions. The most important ones are:

- Internet usage studies should adopt wider time horizons for obtaining data on computer use and Internet use time spans: minimum 20 years and minimum 10 years, respectively,

- the above time ranges (starting at the year 2006) should be systematically extended for later studies,

- based on supplementary research, it may be assumed that the average Internet access delay for Polish computer users is considerably large and amounts at present to (8.3- 3.6= 4.7) 4.7 years.

- the (Internet) entry delay syndrome will show a tendency to fade, i.e. the delay periods will decrease with time, (in Poland, nearly half of the computers in use still lack Internet connectivity), 
- the entry delay syndrome (despite systematic decrease) is of permanent nature, meaning that each new computer user will decide on accessing the Internet after a marked delay.

Results of this study are invaluable for Internet Service Providers (ISPs), allowing for more precise design of network infrastructure, as well as for local administration authorities striving to implement the policy of information society through development of information structures and services and improving Internet access on local and regional scale.

Due to limited space of this publication, more detailed results of the study are not presented, including such issues as user age, income, place of residence, etc. in relation to time span of computer use and Internet use. These results will be systematically presented in the future publications.

\section{References}

Czajkowski, M. (2002). Wielka encyklopedia Internetu i nowych technologi. Krakow: Edition Publ.

Kozyra, C. (2006). Dopasowanie rozkładu beta do danych dotyczacych korzystania z komputera i Internetu w celu estymacji liczebnosci przedzialow klasowych. Wroclaw: AE (University of Economics), (working paper).

Malachowski ,A. (2006) Virtual customer environment (in Polish: Srodowisko wirtualnego klienta) Wroclaw: AE (University of Economics Publ.).

MEGAPANEL (2004) Badania Internetu PBI/Gemius. Retrived June 16, 2005, from http://www.gemius.pl

\section{Biography}

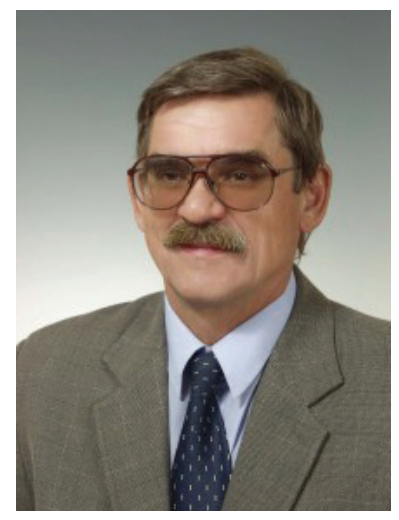

Andrzej Malachowski (*1944), Ph D. (1977) in operation research, university professor (1994). Wroclaw University of Economics (Poland),

Management and Informatics Faculty, Institute of Business Informatics. Head of Business Communication Department. Main scientific interests: business informatics, e-business, business communication. On these fields author and co-author more than 20 books and 80 papers. 12 doctors degree had conferred. 